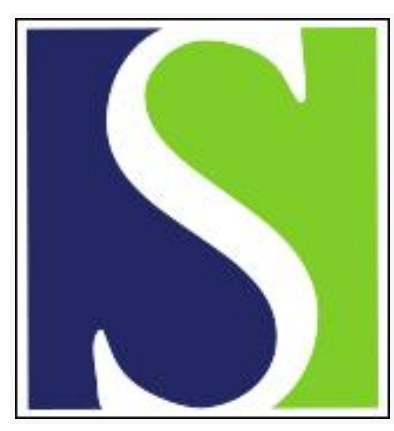

Scand J Work Environ Health 2000;26(3):243-249

https://doi.org/10.5271/sjweh.538

Issue date: Jun 2000

\title{
Occupational determinants for rheumatoid arthritis
}

by Reckner Olsson $\AA$, Skogh T, Wingren $G$

Key terms: asphalt; case-referent study; farmer; nonresponse bias; questionnaire

This article in PubMed: www.ncbi.nlm.nih.gov/pubmed/10901117

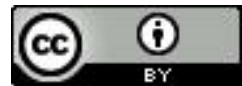




\title{
Occupational determinants for rheumatoid arthritis
}

\author{
by Åsa Reckner Olsson, MD, ${ }^{1}$ Thomas Skogh, MD, ${ }^{2}$ Gun Wingren, PhD'
}

\author{
Reckner Olsson $\AA$, Skogh T, Wingren G. Occupational determinants for rheumatoid arthritis. Scand $J$ Work \\ Environ Health 2000;26(3):243-249.
}

\begin{abstract}
Objectives The aim of the present study was to evaluate possible occupational determinants for rheumatoid arthritis according to lifetime occupational history.

Methods The cases were identified retrospectively from 1980 to 1995 at the University Hospital in Linköping, Sweden. The study comprised 422 cases and 859 randomly selected referents. Exposure data were collected through a postal questionnaire.

Results For men, occupations with increased, although nonsignificant, odds ratios (OR) were farmers or farm workers [OR 1.8, 95\% confidence interval $(95 \% \mathrm{CI}) 1.0-3.5$ ], textile workers (OR 2.0, 95\% CI 0.3-16.2), asphalters (OR 14.0, 95\% CI 1.2-799.0 without latency requirement), and employees at service stations (OR 2.2, 95\% CI 0.5 -9.5). Among the women, hairdressers and beauticians (OR 2.7, 95\% CI 0.8-8.6) had an increased risk for rheumatoid arthritis, as well as those exposed to hairdressing chemicals (OR 3.0, 95\% CI 1.0-9.4) and meat products (OR 2.0,95\% CI 1.0-4.0).

Conclusions Several of the findings in this study are in accordance with those of previous studies. The increased risks of rheumatoid arthritis for asphalters and employees at service stations are however new associations previously not described in the literature.
\end{abstract}

Key terms asphalt, case-referent study, farmers, nonresponse bias, questionnaire.

Rheumatoid arthritis is a chronic inflammatory condition characterized by symmetric polyarthritis. As the disease proceeds, more and more profuse deformation of the joints develops and systemic manifestations can occur. There is also an increased co-morbidity for various conditions, including hematopoetic malignancies (1) and coronary heart disease, and a shortened life-span (2). The present study is the first part of an investigation on determinants of rheumatoid arthritis.

Rheumatoid arthritis has a prevalence of about $0.8 \%$ in European populations ( 3 ) and is $2-3$ times more common among women than men (4). Hormonal factors are believed to influence disease development (5). The pattern of inheritance suggests an effect of more than 1 susceptibility gene, one of them causing a strong human leukocyte antigen DR beta 1 (HLA-DRB1) association, and several studies have shown a selective expansion of synovial T-cell clones in patients with rheumatoid arthritis
(6). The fact that only $15 \%$ of monozygotic twins are concordant for rheumatoid arthritis (7) implies the importance of environmental factors. Environmental determinants that have previously been studied include infectious agents and life-style factors (eg, diet, smoking and alcohol).

Relatively few studies of rheumatoid arthritis have focused on occupational exposures. A Swedish cross-sectional study has shown a number of occupations to be overrepresented among patients with rheumatoid arthritis (eg, outdoor occupations with relatively high physical load among men), while it was indicated that women with rheumatoid arthritis seek employment in less strenuous occupations (8). In a Swedish cohort study, the occurrence of rheumatoid arthritis, among persons reporting the same occupation for at least 10 years, was associated with several occupations, as well as with substantial occupational exposure to organic solvents among

Division of Occupational and Environmental Medicine, Department of Health and Environment, Faculty of Health Science, Linköping University, Linköping, Sweden.

2 Department of Rheumatology, University Hospital, Linköping, Sweden.

Reprint requests to: Dr Åsa Reckner Olsson, Division of Occupational and Environmental Medicine, Department of Health and Environment, Faculty of Health Science, Linköping University, 58183 Linköping, Sweden. [E-mail: asa.reckner-olsson@ymk.liu.se] 
men (9). A Finnish cohort study showed an excess of rheumatoid arthritis among women exposed to raw cotton dust in the textile industry (10), and another Finnish cohort study showed an increased risk among male granite workers exposed to silica (11). Other studies have confirmed the relationship between silica exposure and arthritis $(12,13)$. An analysis of multiple cause mortality has pointed out an excess of arthritis-associated deaths among farmers (14).

The aim of the present study was to evaluate possible occupational determinants of importance for rheumatoid arthritis based on information on lifetime occupational exposure history.

\section{Subjects and methods}

In 1995, cases of rheumatoid arthritis were identified at the Department of Rheumatology at the University Hospital in Linköping in southeastern Sweden. Subjects, 25-75 years old at the time of diagnosis, meeting 1987 revised criteria for the classification of rheumatoid arthritis of the American Rheumatism Association (ARA) (15) during the study period, 1 January 1980 through 30 June 1995, were included. The cases could either have attended the department solely as outpatients or could have had some time of inpatient care. The university hospital functions as a referral practice for the most distant parts of the catchment area, where there are also other, smaller health care units. This practice may have resulted in a varying degree of recruitment of patients from different areas, and therefore the referents were chosen at random from the population living in the geographic area specified by the postal zip codes of the cases. Twice as many referents as cases were included for each year of the study period, and they were frequency-matched for age. This retrospective selection of referents was made possible by the availability of historical population registers in Sweden. Cases and referents born outside the Nordic countries were not included, and the resulting study population comprised 432 prevalent cases of rheumatoid arthritis and 864 referents.

A questionnaire, pretested in a pilot study, was sent to the cases and referents in 1996. Nonrespondents were reminded twice by mailings, and finally by telephone, so that the response rate would be as high as possible. The questionnaire included a question concerning lifelong occupational history, as well as questions concerning specified occupational exposures. Information on time and duration of work was gathered. Other questions covered environmental exposures of possible etiologic interest, such as lifelong residency and leisure-time exposures, educational level, life-style factors, co-morbidity, and the like.

Before the analyses, 10 cases and 8 referents, who could not be traced or were found not to fulfill the established inclusion criteria, were excluded. Two of the referents were found to have rheumatoid arthritis. The final study population therefore comprised 422 cases, among which $79 \%$ were rheumatoid factor (RF) seropositive, and 859 referents.

The occupational titles reported in the questionnaires were classified according to the Nordic classification of occupations, Swedish acronym: NYK (16). For stratified analyses of occupational categories, an unexposed group free of "high-risk occupations" was defined. These "highrisk occupations" were classified as occupations previously associated with rheumatoid arthritis which were also identified in the present study with an odds ratio (OR) of $\geq 1.5$ and involving $>10$ exposed persons (ie, workers exposed to mineral dust, textile workers, farmers and farm workers, metal, foundry and hardware workers, building and construction workers, crane operators and truck drivers, and hairdressers and beauticians). Persons defined as having had a "high-risk occupation" were kept out of the stratified analyses when not being studied as exposed so that a contrast could be obtained for exposure. The category included approximately $37 \%$ of the men and $18 \%$ of the women.

Various latency requirements were tested. No conclusive results were obtained, and, since the latency between the first exposure and the onset of rheumatoid arthritis has often been set in the literature at 20 years, the analyses were performed using this latency between the start of exposure and the date of the ARA diagnosis. Separate analyses were also performed for the cases with seropositive rheumatoid arthritis as a possible means of strengthening the case definition. To be regarded as exposed, subjects were required to have a minimum duration of exposure of 6 months

A comparison between the respondents and nonrespondents was made to evaluate a possible nonresponse bias. For this purpose, information on civil status, median income, and taxable property was collected from the local tax authorities for both the respondents and nonrespondents.

In the stratified analyses, exact odds ratios and $95 \%$ confidence intervals $(95 \% \mathrm{CI})$, based on maximum likelihood estimations, were calculated (17) due to the small numbers in the strata, using the computer program StatXact 3.1 (Cytel Software corporation, Cambridge, Massachusetts, USA). The material was analyzed separately for the men and women and stratified into age groups of $25-40,41-55$, and 56-75 years. Since smoking is a known risk factor for rheumatoid arthritis (18), the material was also stratified into smoking categories of nonsmokers, occasional smokers, and regular smokers. 
When nothing else is stated, the results are presented in the text with regard to both seropositive and seronegative cases, with a latency requirement of 20 years.

To adjust further for possible confounding from occupational determinants, logistic regression analyses were performed using the computer program SPSS (SPSS Inc, Chicago, Illinois, USA). Occupational categories and specific occupational exposures were analyzed in separate models, including age as a continuous variable, smoking as a categorical variable, and the occupational determinants identified in the stratified analyses as having a risk estimate of $\geq 1.5$ or $\leq 0.5$ when the number of exposed subjects (cases plus referents) was at least 10 or when otherwise significantly different from unity.

\section{Results}

Questionnaires were received from 281 cases and 507 referents, the result being a response rate of $67 \%$ and $59 \%$, respectively. Among all the originally included cases, $32 \%$ were men and $68 \%$ were women, reflecting the known male:female ratio. This sex ratio was somewhat different for the responding cases since the women had a lower response rate than the men. For the respondents, the mean age at participation was 62 years for the cases and 58 years for the referents.

The response rate was low when compared with those of questionnaire-based studies performed earlier in Sweden. The results from the comparison of the respondents and nonrespondents are presented in table 1. No major differences were found with regard to year of diagnosis or residency at the time of inclusion.
Increased odds ratios were found for ever smokers as compared with never smokers among both the men (76 exposed cases, 133 referents, OR 2.2, 95\% CI 1.2-4.1) and the women ( 68 exposed cases, 83 referents, OR 1.6, 95\% CI 1.0-2.5) (data not shown in table).

In the stratified analyses, significantly increased risks were seen for farmers and farm workers (29 exposed cases, 36 referents, OR $2.3,95 \%$ exact CI $1.2-4.7$ ) and asphalters (4 exposed cases, 1 referent, OR 14.0, 95\% exact CI 1.2-799.0 without latency requirement). Nonsignificantly increased risks were at first found for a small group with a common exposure to mineral dust [ie, employees in the mining industry, bricklayers and masons, concrete workers, stone cutters, foundry workers and blasters (10 exposed cases, 13 referents, OR $1.8,95 \%$ exact CI 0.7-4.3)], as well as for building and construction workers (12 exposed cases, 18 referents, OR 1.5, 95\% exact CI 0.6-3.6). However, these risks disappeared when the asphalters were excluded from the groups. Nonsignificantly increased risks were also seen for small groups of textile workers ( 3 exposed cases, 3 referents, OR 2.0, 95\% exact $\mathrm{Cr} 0.3-16.2$ ) and employees at service stations ( 4 exposed cases, 3 referents, OR $2.2,95 \%$ exact $\mathrm{CI} 0.5-9.5$ ).

When only seropositive cases were included, there were some changes in the results. For a small group of painters, lacquerers and floor layers, the odds ratio was increased to 1.8 ( 3 exposed cases, 4 referents, $95 \%$ exact CI $0.2-11.7)$. The risk for male bookkeepers, accountants, office cashiers, and estimating clerks increased to 2.8 (6 exposed cases, 8 referents, $95 \%$ exact CI 0.7 10.8 ), while the risk for male textile workers decreased to 1.3 ( 2 exposed cases, 3 referents, OR $1.3,95 \%$ exact CI $0.1-12.5)$.

Table 1. Comparison of the respondents $(\mathrm{N}=788)$ and nonrespondents $(\mathrm{N}=493)$ to the questionnaire mailed to 422 cases and 859 referents. Data refer to the conditions in 1996.

\begin{tabular}{|c|c|c|c|c|c|c|c|}
\hline & $\begin{array}{l}\text { Subjects } \\
\text { (N) }\end{array}$ & $\begin{array}{l}\text { Age, median }_{3} \text { (years) }\end{array}$ & $\begin{array}{c}\text { Married } \\
(\%)^{\mathrm{a}}\end{array}$ & $\begin{array}{l}\text { Single } \\
(\%)^{2}\end{array}$ & $\begin{array}{l}\text { Unknown } \\
(\%)^{\mathrm{a}}\end{array}$ & $\begin{array}{l}\text { Income } \\
\text { (median) }\end{array}$ & $\begin{array}{l}\text { No taxable property } \\
\text { or income }(\%)^{\text {a, b }}\end{array}$ \\
\hline \multicolumn{8}{|l|}{ Cases } \\
\hline \multicolumn{8}{|l|}{ Men } \\
\hline Respondents & 102 & 64 & 72 & 22 & 6 & 141900 & 92 \\
\hline Nonrespondents & 33 & 62 & 58 & 39 & 3 & 128300 & 91 \\
\hline \multicolumn{8}{|l|}{ Women } \\
\hline Respondents & 179 & 62 & 62 & 33 & 5 & 106500 & 90 \\
\hline Nonrespondents & 108 & 67 & 44 & 47 & 9 & 91400 & 94 \\
\hline \multicolumn{8}{|l|}{ Referents } \\
\hline \multicolumn{8}{|l|}{ Men } \\
\hline Respondents & 248 & 58 & 68 & 27 & 5 & 189550 & 87 \\
\hline Nonrespondents & 158 & 56 & 50 & 44 & 6 & 156800 & 91 \\
\hline \multicolumn{8}{|l|}{ Women } \\
\hline Respondents & 259 & 57 & 62 & 35 & 3 & 121100 & 91 \\
\hline Nonrespondents & 194 & 59 & 56 & 39 & 5 & 108750 & 93 \\
\hline
\end{tabular}

${ }^{a}$ Data collected from the local tax authorities.

b Fiscal year of 1996 (Swedish krona). 
Stratified analyses were also performed for specific occupational exposures. For the men, significantly increased risks were seen for exposure to crops (44 exposed cases, 62 referents, OR 2.0, 95\% CI 1.1-3.4), asphalt ( 7 exposed cases, 1 referents, OR 11.7, 95\% exact CI 1.4-543.9) and fertilizers (30 exposed cases, 39 referents, OR 2.0, 95\% exact CI $1.1-3.7$ ). The risks were also increased for exposure to pesticides (11 exposed cases, 12 referents, OR 2.1, 95\% exact CI 0.8-5.7), hydraulic oil (13 exposed cases, 16 referents, OR 1.8, 95\% exact $\mathrm{CI} 0.7-4.3)$, and for a small group exposed to textile dust ( 3 exposed cases, 2 referents, OR $3.1,95 \%$ exact CI 0.3-39.1). There were no major changes in the results when only seropositive cases were included in the analyses, besides an increased risk for exposure to mineral dust (14 exposed cases, 21 referents, OR 1.8, $95 \%$ exact CI $0.8-4.1)$.

The results from the logistic regression analyses for the men can be seen in tables 2 and 3. Most of the findings from the stratified analysis prevailed, besides the lower risks found for farmers and for exposure to hydraulic oil, crops, fertilizers and pesticides. For the women, the logistic regression analyses showed increased risks for hairdressers and beauticians [logistic odds ratio (LOR) 2.7, 95\% CI 0.8-8.6], for exposure to hairdressing chemicals (LOR 3.0, 95\% CI 1.0-9.4), and for the handling of meat products (LOR $2.0,95 \%$ CI $1.0-4.0$ ). The risks for smoking decreased in both models for both genders, although the risks were still significantly or almost significantly increased (data not shown in tables).

Table 2. Multivariate analysis of occupations of risk for rheumatoid arthritis with adjustment for age and smoking among men, 102 cases and 248 referents. Odds ratios (OR) for 83 cases with a positive rheumatoid factor are also shown. The latency requirement was 20 years. $(95 \% \mathrm{Cl}=95 \%$ confidence interval)

\begin{tabular}{|c|c|c|c|c|c|c|c|c|}
\hline \multirow[t]{2}{*}{ Occupation ${ }^{2}$} & \multicolumn{4}{|c|}{ All cases } & \multicolumn{4}{|c|}{ Seropositive cases } \\
\hline & $\begin{array}{l}\text { Number of } \\
\text { exposed } \\
\text { cases }\end{array}$ & Referents & $O R^{b}$ & $95 \% \mathrm{Cl}$ & $\begin{array}{l}\text { Number of } \\
\text { exposed } \\
\text { cases }\end{array}$ & Referents & $O R^{b}$ & $95 \% \mathrm{Cl}$ \\
\hline Asphalters $^{\mathrm{C}}(793)$ & 4 & - & $\rightarrow \infty$ & & 4 & - & $\rightarrow \infty$ & \\
\hline Machine and engine repairers (753) & 9 & 11 & 2.1 & $0.8-5.6$ & 8 & 11 & 2.1 & $0.8-5.9$ \\
\hline Packers, warehouse workers $(881-889)$ & 7 & 8 & 1.9 & $0.6-6.2$ & 6 & 8 & 2.2 & $0.6-7.5$ \\
\hline Farmers and farm workers $(400,402,411,412)$ & 29 & 36 & 1.8 & $1.0-3.5$ & 23 & 36 & 1.9 & $0.9-3.9$ \\
\hline $\begin{array}{l}\text { Bookkeepers, accountants, office cashiers, } \\
\text { estimating clerks }(231-249,291-299)\end{array}$ & 6 & 8 & 1.7 & $0.5-5.6$ & 6 & 8 & 2.2 & $0.7-7.3$ \\
\hline Metal, foundry and hardware workers $(731-739)$ & 7 & 8 & 1.6 & $0.5-5.2$ & 6 & 8 & 1.7 & $0.5-6.3$ \\
\hline Millers, bakers (821-822) & 4 & 6 & 1.5 & $0.4-5.7$ & 3 & 6 & 1.4 & $0.3-6.2$ \\
\hline Engineers $(001-009)$ & 5 & 25 & 0.5 & $0.2-1.3$ & 3 & 25 & 0.3 & $0.1-1.2$ \\
\hline
\end{tabular}

a NYK (Nordic classification of occupations) codes in parentheses.

- OR derived from the multiple logistic regression adjusted for age, smoking, and occupational risk factors identified in the stratified analyses as having risk estimates of $\geq 1.5$ and $\leq 0.5$ when the number of exposed subjects (cases plus referents) was at least 10 or when otherwise significantly different from unity.

c None or few exposed referents in strata, OR towards infinity.

Table 3. Multivariate analysis of specific occupational exposures of risk for rheumatoid arthritis with adjustment for age and smoking among men, 102 cases and 248 referents. Odds ratios (OR) for 83 cases with a positive rheumatoid factor are also shown. The latency requirement was 20 years. (95\% $\mathrm{Cl}=95 \%$ confidence interval)

\begin{tabular}{|c|c|c|c|c|c|c|c|c|}
\hline \multirow[t]{2}{*}{ Exposure } & \multicolumn{4}{|c|}{ All cases } & \multicolumn{4}{|c|}{ Seropositive cases } \\
\hline & $\begin{array}{l}\text { Number of } \\
\text { exposed } \\
\text { cases }\end{array}$ & Referents & $\mathrm{OR}^{\mathrm{a}}$ & $95 \% \mathrm{Cl}$ & $\begin{array}{c}\text { Number of } \\
\text { exposed } \\
\text { cases }\end{array}$ & Referents & $O R^{a}$ & $95 \% \mathrm{Cl}$ \\
\hline Asphalt $t^{b}$ & 7 & 1 & $\rightarrow \infty$ & $=$ & 7 & 1 & $\rightarrow \infty$ & r \\
\hline Impregnating agents & 5 & 5 & 1.8 & $0.1-21.6$ & 5 & 5 & 2.8 & $0.2-37.7$ \\
\hline Asbestos & 12 & 13 & 1.8 & $0.6-5.4$ & 8 & 13 & 1.0 & $0.2-4.8$ \\
\hline Meat products & 6 & 7 & 1.6 & $0.5-5.7$ & 5 & 7 & 2.1 & $0.6-7.6$ \\
\hline Crops & 44 & 62 & 1.5 & $0.6-3.7$ & 37 & 62 & 1.9 & $0.7-4.9$ \\
\hline Hydraulic oil & 13 & 16 & 1.4 & $0.5-3.6$ & 11 & 16 & 1.3 & $0.4-4.0$ \\
\hline Fertilizers & 30 & 39 & 1.2 & $0.4-3.6$ & 23 & 39 & 0.9 & $0.3-2.9$ \\
\hline Pesticides & 11 & 12 & 1.2 & $0.4-4.1$ & 9 & 12 & 1.6 & $0.5 .-5.6$ \\
\hline
\end{tabular}

a OR derived from multiple logistic regression adjusted for age, smoking, and occupational risk factors identified in the stratified analyses as having risk estimates of $\geq 1.5$ and $\leq 0.5$ when the number of exposed subjects (cases plus referents) was at least 10 or when otherwise significantly different from unity.

None or few exposed referents in strata, OR towards infinity. 


\section{Discussion}

This case-referent study, using individual exposure data and information on lifetime occupational history, has a design that enables the establishment of a temporal relationship between exposure and effect.

The response rate in the present study was low. The questionnaire was extensive, but did not otherwise differ much from questionnaires previously used at the Division of Occupational and Environmental Medicine, with response rates of $80-90 \%$. The present study population was somewhat older than those of earlier studies, and difficulties to write due to sequelae of rheumatoid arthritis may have stopped cases from participating. A growing reluctance in the general population to participate in questionnaire surveys has also been seen in Sweden (19).

It has been shown that nonrespondents often differ from respondents both with regard to etiologic factors and outcome, like morbidity and mortality, a phenomenon that might cause a nonresponse bias. Such a bias is not dependent on the degree of participation, but rather on whether factors of importance for the hypotheses tested are unequally distributed among the cases and referents in the responding versus the nonresponding groups. The presence of such bias in a study with a low response rate can, however, to a large extent, affect the interpretation of the results.

Nonrespondents have previously been shown to be more likely to belong to a lower social class (20) and to be unemployed or have uncertain employment (21). The lower income found among the nonrespondents in the present study is in accordance with this trend and may reflect a lower educational level and the presence of more unskilled and blue-collar workers in this group. The cases also earned less than the referents among both the respondents and nonrespondents, a finding which may reflect a higher degree of impairment of work and dependence on sickness benefits due to rheumatoid arthritis. Socioeconomic deprivation has not been associated with susceptibility to rheumatoid arthritis (22), but, when followed for 2 years, cases of recent onset of rheumatoid arthritis had a prevalence of early full retirement of $37 \%$, and a third of those still holding a paid position had reduced ability to work (23). However, the decrease in income of the nonrespondents compared with the respondents was of nearly the same magnitude for both the cases and the referents in the present study, and therefore there was no clear evidence of a selective loss of cases in occupations indicated by lower income.

The use of prevalent cases of rheumatoid arthritis, gathered from medical records of patients currently attending the Department of Rheumatology, may have resulted in selection. For example, the patients who had died before the time of inclusion in the study may have been affected by more severe rheumatic disease, and the least severe cases may have been referred from the University Hospital to other health care units.

When various latency requirements were tested, the results indicated that the relevant latency period may change with the occupational exposure studied. It is plausible that different kinds of occupational determinants could cause the disease after different time courses. The chosen latency requirement must therefore be regarded as a compromise aiming at a better possibility for comparison with earlier findings.

The question concerning lifelong occupational history can be considered as a reliable classification of occupational belonging, probably not affected by recall bias. However, the exact nature and degree of the exposure in each occupation is not known and should be regarded as an indirect estimate. Most occupations involve multiple exposures, many of which may have changed over the years, due to the introduction of preventive measures, new chemicals, and the like.

Several of the findings in the present study were based on rather small exposure categories, as indicated by the broad confidence intervals. Some findings were however in accordance with those of previous studies and lend support to earlier findings, for example, the increased risks for farmers and farm workers $(8,9,14)$, machine and engine repairers (8), and office workers [eg, bookkeepers and office cashiers (9)] among the men. Female textile workers have previously been shown to have increased risks for rheumatoid arthritis (10), while the present study showed an excess risk for a small group of men in such occupations. The opposite was seen for hairdressers and beauticians, previously mentioned as a high-risk occupation for men (9), whereas in this study we found it to be of high risk for women. In this connection it is interesting to note that not only intracutaneous, but also percutaneous exposure to mineral oils in commercial cosmetic products can induce arthritis in an arthritis-prone rat strain (24).

An increased risk has been reported earlier for men exposed to a substantial amount of organic solvents (9), and exposure to solvents and other petroleum products may explain the increased odds ratios found for employees at service stations. However, we found no increased risk for exposure to solvents in itself. An increased risk for rheumatoid arthritis has previously been observed for butchers (8), a finding which corresponds to the increase in risk in our study for both the men and women with exposure to meat products.

Several occupations associated with rheumatoid arthritis, both previously and in our study, include exposure to aerosols (eg, farmers and textile workers industrially exposed to organic fibers). The risk may be conferred to a biologically active agent in the dust particle itself or by contamination of the dust with, for example, 
Gram-negative bacteria, which may cause an endotoxinmediated cellular release of cytokines, activation of macrophages, and lymphocytes resulting in local inflammation and systemic reactions $(25,26)$.

Silica is known to cause an immune response (27), and inhaled silica may also cause a decreased resistance to infections (11). Workers exposed to mineral dust (11, 12, 13) and concrete and construction workers (9) have previously been identified as having an increased risk for rheumatoid arthritis. However, in our study the increase in risks associated with such occupations was found to be carried by asphalters. This association has previously not been described. Contact with asphalt involves multiple exposures, such as coal tar, crude oils, polycyclic aromatic hydrocarbons and bitumen fumes, and asphalters are also exposed, for example, to ultraviolet radiation, mineral dust, and engine exhaust. Some of the exposures, like coal tar, are also found in smoking fumes, previously mentioned as a possible risk factor for the development of rheumatoid arthritis. Arthritis can also be induced in rats by adjuvants like mineral oils and organic lipids $(28,29)$.

People are likely to have different susceptibilities to rheumatoid arthritis due to genetic, hormonal, and environmental factors. The etiopathogenic mechanisms are probably complex and depend on both internal and external determinants, making rheumatoid arthritis an end point of several possible combinations of contributing factors. The exact role of occupational factors in the etiology of rheumatoid arthritis is not clear. Neither is the causal factor of interest clearly identified for any of the occupations reported to increase the risk for rheumatoid arthritis. However, the fact that the odds ratios were increased in many analyses when only seropositive cases of rheumatoid arthritis were included can be regarded as strengthening the possibility for a true causal effect from these determinants. Our results also indicate that occupational factors may be of greater importance for men than for women.

\section{Acknowledgments}

The study was supported financially by the Swedish Council for Work Life Research and the Östergötland county council.

The authors thank Mrs Azra Mujkic for her assistance with the data coordination and Professor Olav Axelson for providing support and helpful comments on the manuscript.

\section{References}

1. Myllykangas-Luosujärvi R, Aho K, Isomäki H. Mortality from cancer in patients with rheumatoid arthritis. Scand $J$
Rheumatol 1995;24:76-8.

2. Myllykangas-Luosujärvi R, Aho K, Kautiainen H, Isomäki H. Shortening of life span and causes of excess mortality in a population-based series of subjects with rheumatoid arthritis. Clin Exp Rheumatol 1995;13:149-53.

3. Silman AJ, Hochberg MC. Rheumatoid arthritis. In: Silman AJ, Hochberg MC. Epidemiology of the rheumatic diseases. 1st ed. Oxford: Oxford Medical Publications, Oxford University Press, 1993:7-68.

4. Linos A, Worthington JW, O'Fallon M, Kurland LT. The epidemiology of rheumatoid arthritis in Rochester, Minnesota: a study of incidence, prevalence and mortality. Am J Epidemiol 1980;111:87—98.

5. Masi AT, Feigenbaum SL, Chatterton RT. Hormonal and pregnancy relationships for rheumatoid arthritis: convergent effects with immunologic and microvascular systems. Semin Arthritis Rheum 1995;25:1-27.

6. Weyand CM, Goronzy JJ. The molecular basis of rheumatoid arthritis. J Mol Med 1997;75:772-85.

7. Silman AJ, MacGregor AJ, Thomson W, Holligan S, Carthy D, Farhan A, et al. Twin concordance rates for rheumatoid arthritis: results from a nationwide study. $\mathrm{Br} \mathrm{J}$ Rheumatol 1993;32:903-7.

8. Hellgren $L$. The prevalence of rheumatoid arthritis in occupational groups. Acta Rheum Scand 1970;16:106-13.

9. Lundberg I, Alfredsson L, Plato N, Sverdrup B, Klareskog L, Kleinau S. Occupation, occupational exposure to chemicals and rheumatological disease. Scand J Rheumatol 1994; 23:305-10.

10. Koskela RS, Klockars M, Järvinen E. Mortality and disability among cotton mill workers. Br J Ind Med 1990;47:384—91.

11. Klockars M, Koskela R-S, Järvinen E, Kolari PJ, Rossi A. Silica exposure and rheumatoid arthritis: a follow-up study of granite workers 1940-81. BMJ 1987;294:997-1000.

12. Steenland K, Nowlin S, Ryan B, Adams S. Use of multiple cause mortality data in epidemiologic analyses: US rate and proportion files developed by the National Institute for Occupational Safety and Health and the National Cancer Institute. Am J Epidemiol 1992;136:855—62.

13. Steenland K, Brown D. Mortality study of goldminers exposed to silica and non-asbestiform amphibole minerals: an update. Am J Ind Med 1995;27:217-29.

14. Milham Jr S. Using multiple cause of death coding in occupational mortality studies. Am J Ind Med 1988;14:341-4.

15. Arnett FC, Edworthy SM, Bloch DA, McShane DJ, Fries JF, Cooper NS, et al. The American Rheumatism Association 1987 revised criteria for the classification of rheumatoid arthritis. Arthritis Rheum 1988;31:315-24.

16. Arbetsmarknadsstyrelsen. Nordisk Yrkes Klassificering Svensk grundstandard [Nordic classification of occupations] Stockholm: Arbetsmarknadsstyrelsen [The National Labour Market Board], 1983.

17. Gart J. Point and interval estimation of the common odds ratio in the combination of $2 \times 2$ tables with fixed marginals. Biometrika 1970;57:471-5.

18. Wilson $\mathrm{K}$, Goldsmith $\mathrm{CH}$. Does smoking cause rheumatoid arthritis? J Rheumatol 1999;26:1-3.

19. Bergdahl M, Ekman S, Lindberg A, Rennermalm M. Bortfallsbarometern no 6 [The non-response monitor no 6]. Statistics Sweden, 1991. R \& D report no 13.

20. Sheikh K, Mattingly S. Investigating non-response bias in mail surveys. J Epidemiol Community Health 1981;35:2936.

21. Sheikh K. Predicting risk among non-respondents in prospec- 
tive studies. Eur J Epidemiol 1986;2:39—43.

22. Bankhead C, Silman A, Barrett B, Scott D, Symmons D. Incidence of rheumatoid arthritis is not related to indicators of socioeconomic deprivation. J Rheumatol 1996;23:2039_42.

23. Eberhardt K, Larsson BM, Nived K. Early rheumatoid arthritis - some social, economical and psychological aspects. Scand J Rheumatol 1993;22:119-23.

24. Sverdrup B, Klareskog L, Kleinau S. Common commercial cosmetic products induce arthritis in the D4 rat. Environ Health Perspect 1998;106:27-32.

25. Rylander R. Organic dusts - from knowledge to prevention. Scand J Work Environ Health 1994;20 special issue: 116-22.

26. Rylander R, Jacobs RR, editors. Organic dusts: exposure, effects, and prevention. Chicago (IL): Lewis Publishing Inc, 1994.

27. Haustein UF, Ziegler V, Herrman K, Mehlhorn J, Schmidt C. Silica-induced scleroderma. J Am Acad Dermatol 1990; 22:444-8.

28. Lorentzen JC, Glaser A, Jacobsson L, Galli J, Fakhrai-rad H, Klareskog L, et al. Identification of rat susceptibility loci for adjuvant oil-induced arthritis. Proc Natl Acad Sci 1998; 95:6383-7.

29. Lorentzen JC. Identification of arthritogenic adjuvants of self and foreign origin. Scand J Immunol 1999:49:45—50.

Received for publication: 9 April 1999 